\title{
Association between inflammatory cytokines and the risk of post-stroke depression, and the effect of depression on outcomes of patients with ischemic stroke in a 2-year prospective study
}

\author{
JIAN-TONG JIAO*, CHAO CHENG*, YING-JUN MA*, JIN HUANG, MIN-CHAO DAI, \\ CHEN JIANG, CHENG WANG and JUN-FEI SHAO
}

Department of Neurosurgery, Wuxi People's Hospital of Nanjing Medical University, Wuxi, Jiangsu 214023, P.R. China

Received April 8, 2015; Accepted May 12, 2016

DOI: $10.3892 / \mathrm{etm} .2016 .3494$

\begin{abstract}
The association between inflammatory cytokines and the risk of post-stroke depression (PSD) remains unclear. The aim of the present study was to investigate this association and the effect of PSD on the outcomes of ischemic stroke patients. A total of 355 patients who had experienced ischemic stroke participated in inflammatory cytokine detection by ELISA, in addition to depression, quality of life (QOL) and body performance testing. Cox regression was used to evaluate the associations between PSD risk, inflammatory cytokines and the outcomes of patients. Measurement data was evaluated using Student's t test, and counted data was measured by $\chi^{2}$ test. The incidence of PSD during the 2-year follow-up was $23.1 \%$. The risk of PSD elevated with increased interleukin (IL)-6 expression levels [hazard ratio (HR) $=3.18 ; 95 \%$ confidence interval (CI), 1.37-7.36] following the adjustment of confounders. However, no significant associations were identified between PSD and other inflammatory cytokines. QOL and body performance in the depressed group were significantly worse compared with those in the non-depressed group. The risk of stroke recurrence in patients with depression increased two-fold compared with patients without depression $\left(\mathrm{HR}=2.020 ; 95 \% \mathrm{CI}, 1.123-3.635 ; \mathrm{P}_{\text {trend }}=0.019\right)$. No significant associations between PSD and the risk of mortality $(\mathrm{HR}=1.497 ; 95 \% \mathrm{CI}, 0.547-4.098)$ were observed. In conclusion, depression is prevalent in patients following ischemic stroke. IL-6 is positively associated with the risk of PSD, and may predict its development in patients following ischemic
\end{abstract}

Correspondence to: Professor Jun-Fei Shao, Department of Neurosurgery, Wuxi People's Hospital of Nanjing Medical University, 229 Qingyang Road, Wuxi, Jiangsu 214023, P.R. China E-mail: wxhneurosurgery@126.com

\section{${ }^{*}$ Contributed equally}

Key words: ischemic stroke, post-stroke depression, inflammatory cytokines, interleukin- 6 , outcomes stroke. PSD correlates with outcomes of patients, and the effective management of PSD may improve the prognosis of patients.

\section{Introduction}

In developed countries, stroke is the second leading cause of mortality and disease burden (1). Depression is one of the most frequent affective disorders that develops following a stroke (2). An estimation of the frequency of depression in patients with stroke is up to $33 \%$ (3). The association between stroke and depression has been well established and is suggested to be bidirectional (4); stroke can increase the risk of depression (5) and, in turn, depression independently increases the risk of developing stroke (6). The presence of depression in patients experiencing stroke has been associated with poor outcome and higher mortality (7-9). This suggests that the recognition and diagnosis of depression in patients experiencing stroke is important and necessary.

Upregulation of inflammatory cytokines has been suggested to be an important mechanism underlying clinical depression (10). The presence of depression is reported to be associated with an increase in expression levels of a number of inflammatory cytokines in serum, such as interleukin (IL)-1 $\beta$, IL-2, IL-6 and C-reactive protein (CRP) (11-18). However, a number of studies have not found a significant association between these factors, and other studies have only observed the phenomenon in a defined population (19). Acute ischemic stroke is known to induce an inflammatory response in the majority of patients (20). Early elevations in numerous proinflammatory cytokines can be detected in the cerebrospinal fluid and plasma of patients, independent of other medical comorbidities, including infections, malignancy and autoimmune disease (21). This evidence suggests that inflammatory cytokines may also serve an important role in the development of post-stroke depression (PSD).

To date, the association between inflammatory cytokines and PSD remains controversial. It has been observed that fatigue following stroke is significantly associated with high serum CRP expression levels (22). In addition, it has been reported that IL- 6 and tumor necrosis factor- $\alpha$ (TNF- $\alpha$ ) are increased in patients with PSD, compared with patients who 
had experienced ischemic stroke but did not develop depression (23). These results imply that depressive symptoms induce the expression of inflammatory factors. However, in one study, the association between PSD and serum levels of molecular markers of inflammation [IL-1 $\beta$, IL-6, intracellular adhesion molecule 1 , TNF- $\alpha$, leptin, high-sensitivity CRP (hs-CRP) and neurotrophic factors, such as brain-derived neurotrophic factor] were investigated, and only leptin was identified to be significantly associated with the risk of PSD (24). Furthermore, high concentrations of serum CRP are reported to be associated with lower post-stroke global cognition (21). In addition, a significant association between serum IL-18 and PSD has been identified, but not between PSD, IL-6 and TNF- $\alpha$ (25). These results suggest that the expression of cytokines resulting from stroke may be the cause of PSD.

Considering the potential association between inflammatory cytokines and PSD, and methodological problems such as case-control design and restricted numbers of stroke events in the small number of previously reported studies (20-24), in this prospective study the aim was to investigate the association between inflammatory cytokines (CRP, IL-1 $\beta$, IL-2, IL-6 and TNF- $\alpha$ ) and the risk of PSD. In addition, the effect of PSD on the outcomes of patients is investigated.

\section{Materials and methods}

Patients. The participants of the present study consisted of 355 patients (205 males and 150 females), with a diagnosis of ischemic stroke, treated at Wuxi People's Hospital of Nanjing Medical University (Wuxi, China) between February 2009 and March 2011, who were followed-up to March 2013. The mean [standard deviation, (SD)] age for males was 53.2 (10.9) years and 51.8 (13.3) years for females. Patients were enrolled by the researcher at the start of ischemic stroke treatment; the radiological diagnosis of ischemic stroke was performed by computed tomography (CT) or magnetic resonance imaging (MRI), and the sizes of infarctions were measured (cut-off, $2.0 \mathrm{~cm}$ ). There were 168 patients with ischemic stroke located in the right hemisphere and 187 patients with ischemic stroke located in the left hemisphere. Eligibility criteria included a primary diagnosis of ischemic stroke, capability of completing questionnaires and participation in the program. Patients were excluded if they had previously experienced an ischemic stroke and/or had a history of depression and/or were being treated for depression. Prior to discharge from the hospital, the patients and/or their relatives were trained to fulfill questionnaires.

The study was approved by the Ethics Committee of Nanjing Medical University and was supported by patients and/or their relatives.

Assessment of ischemic stroke severity. Patients underwent the National Institutes of Health Stroke Scale (NIHSS) test to assess the severity of ischemic stroke at admission (26). The scores of the NIHSS test were attained. The severity of stroke was graded as mild (NIHSS, $\leq 8$ ), moderate (NIHSS, 9-15), or severe (NIHSS, $\geq 16$ ). If the patients with aphasia or severe stroke could not fulfill questionnaires, they were excluded from the study prior to enrollment.
Assessment of depression. Mental status was assessed using the Beck Depression Inventory-Second Edition (BDI-II) (27), which is a widely used self-administered scale consisting of 21 items to evaluate the severity of depressive symptoms. As recommended in the clinical manual, final scores of $\geq 14$ were considered indicative of clinically significant elevations in depressive symptoms. If depression was indicated, psychosocial intervention was recommended. If depression was serious, general medical advice was provided. The test was performed by doctors at admission. If the patients had symptoms of depression, they were excluded from the study. During follow-up, if the mental status of patients had changed, the tests were performed by themselves or their relatives.

Assessment of quality of life (QOL) and body performance. The Persian version of the WHOQOL-BREF questionnaire contains 26 items (28). The first two items on the questionnaire are of general health and health-related quality of life. The other 24 items combine four domains: i) Physical capacity; ii) psychological well-being; iii) social association; and iv) environment. In the current study, the total scores of QOL were obtained by combining the scores.

The Karnofsky Performance Status scale (KPS) is one of the instruments used to measure the body performance of patients (29). This scale indicates a person's ability to work, perform physical activity, and care for themselves. One trained physician assigned scores from 0 (did not survive) to 100 (healthy) at 10-unit intervals for each level.

These two scales were performed by doctors at admission and by patients or their relatives at follow-up at 12 months.

Measurement of serum expression levels of CRP, IL-1 $\beta, I L-2$, $I L-6$ and $T N F-\alpha$. Fasting serum samples were collected at the study baseline. The fasting time of all patients was $>8 \mathrm{~h}$ and samples were collected on the morning of the second day after admission. No patients were undergoing treatment at the time of blood sampling. The blood samples were kept on ice prior to centrifugation at $206 \mathrm{x} \mathrm{g}$ for $10 \mathrm{~min}$ at $4{ }^{\circ} \mathrm{C}$. Then, plasma was stored at $-70^{\circ} \mathrm{C}$ until analysis. Laboratory personnel were blinded to the case, control and quality control sample status at the time of analysis. Serum expression levels of CRP, IL-1 $\beta$, IL- 2 , IL- 6 and TNF- $\alpha$ were measured using ELISA kits. The ELISA kits for IL-1 $\beta$, IL-2, IL-6 and TNF- $\alpha$ were purchased from BD Biosciences (San Diego, CA, USA). The ELISA kits for CRP were purchased from Thermo Fisher Scientific, Inc. (Waltham, MA, USA). The sensitivities of the tests were $0.5,2,3,1.5$ and $3 \mathrm{pg} / \mathrm{ml}$ for TNF- $\alpha$, CRP, IL-1 $\beta$, IL- 2 , IL- 6 and TNF- $\alpha$, respectively. The intra- and inter-assay coefficients of variations were all $<6 \%$. Serum concentrations were categorized as quartiles based on the distributions among controls. The lowest quartile was used as the reference category. Hazard ratio (HR) and 95\% confidence intervals (CIs) were calculated to estimate the relative risk using Cox regression proportional hazards models. In the multivariate analyses, age, gender, education, smoking, alcohol assumption, marriage, hemisphere, stroke severity, infarct size and infarct sites were included as covariates. Linear trend of association was evaluated by including categorical trend variables in the regression model. 


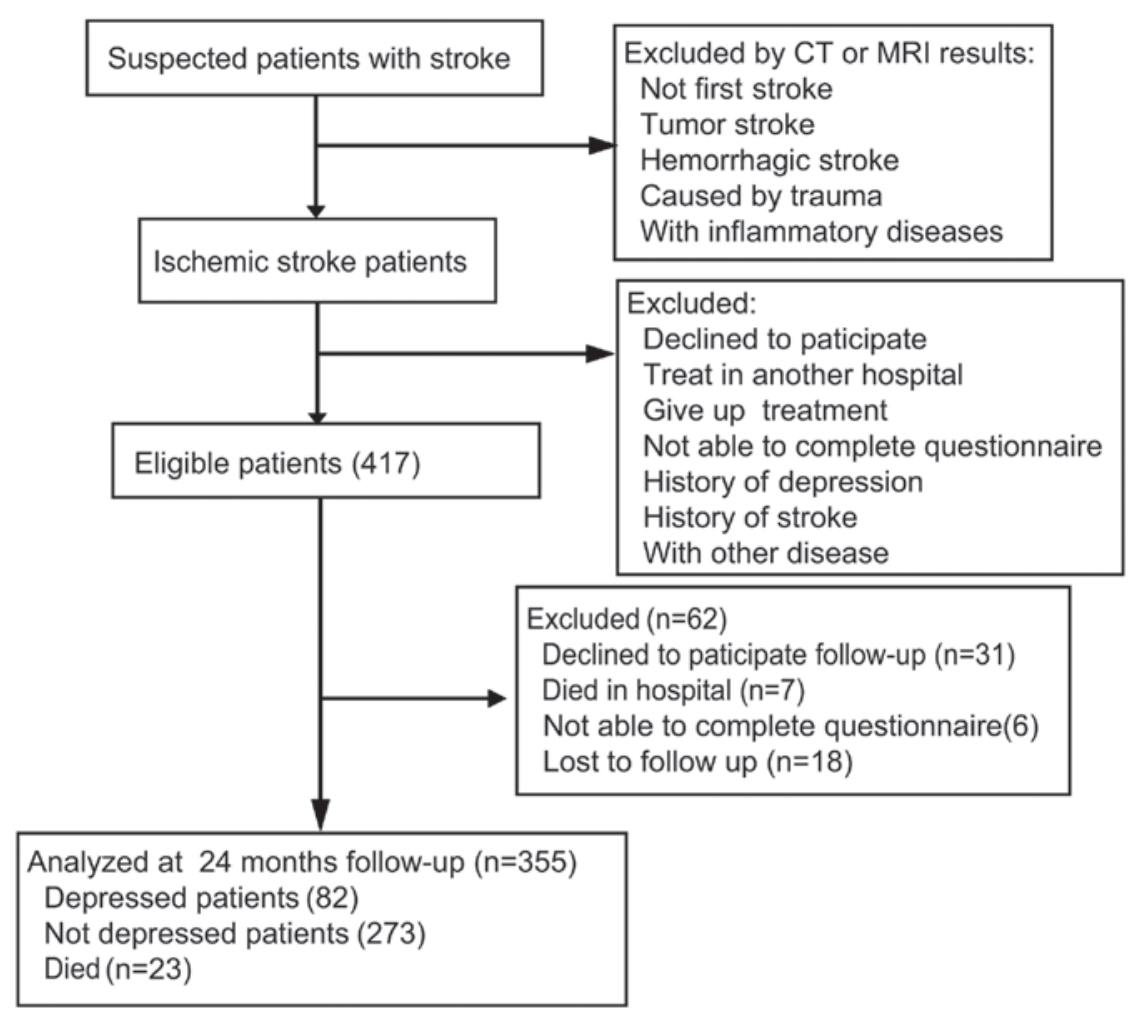

Figure 1. Diagram of participants' progress throughout the study.

Assessment of survival. The survival status and time of each patient was recorded from the date of hospital discharge to mortality or to the end of follow-up in the year 2013. The information on the survival (gross survival) was obtained by mail or telephone follow-up.

Statistical analysis. Group differences and continuous variables were tested using Student's t-test and $\chi^{2}$ test. Cox regression model was used to estimate the association between serum concentrations of CRP, IL-1 $\beta$, IL-2, IL- 6 and TNF- $\alpha$, the risk of depression, and the association between PSD and risk of outcomes in ischemic stroke patients. All statistical analyses were performed using SPSS version 16.0 (SPSS, Inc., Chicago, IL, USA). $\mathrm{P}<0.05$ was considered to indicate a statistically significant difference.

\section{Results}

Baseline patient characteristics. A total of 417 patients participated in blood sample collection for inflammatory cytokine testing. During follow-up, the BDI-II, QOL and KPS tests were performed on the patients. At the end of follow-up, $355(85.1 \%)$ patients were identified as eligible. Reasons for non-participation are presented in Fig. 1. A total of 82 patients were identified as depressed, and 273 patients were identified as non-depressed by the BDI-II test after discharge. The incidence of depression in patients following ischemic stroke was $23.1 \%$. At baseline, the depressed and non-depressed groups were compared with regards to demographic variables and clinical characteristics (Table I). Baseline demographic values between groups were not statistically different, with the exception of age; patients $<50$ years of age in the depressed group were significantly higher compared with the non-depressed group $(\mathrm{P}=0.003$; Table I).

PSD and serum inflammatory cytokines concentrations. The result in Table II show the associations between the risk of PSD in patients following ischemic stroke and circulating concentrations of inflammatory cytokines (CRP, IL-1 $\beta$, IL-2, IL- 6 and TNF- $\alpha$ ). In quartile analysis, the association between depression status and inflammatory cytokines expression levels were analyzed and stratified by quartile cut-points. There were clear associations between IL-6 and PSD in patients following ischemic stroke, comparing the highest with the lowest quartile (HR=3.23; 95\% CI, 1.45-7.20). Although the strength of the association between serum IL-6 expression levels and the risk of PSD was slightly attenuated after adjusting for age, gender, education, internet use, smoking, alcohol assumption, marriage, hemisphere and infarct locations, a significant association was observed between serum IL-6 expression levels and the outcome comparing the highest with the lowest quartiles (HR=3.18; 95\% CI 1.37-7.36; $\mathrm{P}=0.011$ ). However, no significant association was identified between the risk of PSD and other cytokines, such as CRP, IL-1 $\beta$, IL-2 and TNF- $\alpha$. Although the risk estimates increased with every next quartile in quartile analysis for CRP, IL- $1 \beta$, IL-2 and TNF- $\alpha$, linear trends for the association of the expression levels of these cytokines with the risk of PSD were not significant (Table II).

Effects of PSD on body performance and quality of life in patients. At the time of admission, the mean KPS in the depressed and non-depressed groups were 54.512 (SD, 13.440) and 55.348 (SD, 15.880), respectively, and there was no significant difference in KPS in the depressed group compared 
Table I. Characteristics of the study population at baseline.

\begin{tabular}{|c|c|c|c|}
\hline Characteristic & Depressed (n) & Not depressed (n) & P-value \\
\hline Age (years) & & & 0.003 \\
\hline$\geq 50$ & 36 & 171 & - \\
\hline$<50$ & 46 & 102 & - \\
\hline Gender & & & 0.352 \\
\hline Male & 51 & 154 & - \\
\hline Female & 31 & 119 & - \\
\hline Marriage & & & 0.762 \\
\hline Married & 72 & 243 & - \\
\hline Unmarried & 10 & 30 & - \\
\hline Education & & & 0.730 \\
\hline Primary & 29 & 105 & - \\
\hline Secondary & 31 & 106 & - \\
\hline Advanced & 22 & 62 & - \\
\hline Smoking & & & 0.219 \\
\hline Yes & 26 & 107 & - \\
\hline No & 56 & 166 & - \\
\hline Alcohol & & & 0.143 \\
\hline Yes & 22 & 97 & - \\
\hline No & 60 & 176 & - \\
\hline Hemisphere & & & 0.190 \\
\hline Left & 38 & 149 & - \\
\hline Right & 44 & 124 & - \\
\hline Infarct location & & & 0.207 \\
\hline Frontal & 34 & 80 & - \\
\hline Temporal & 19 & 85 & - \\
\hline Parietal & 17 & 63 & - \\
\hline Occipital & 12 & 45 & - \\
\hline Stroke severity & & & 0.106 \\
\hline Mild & 38 & 141 & - \\
\hline Moderate & 33 & 69 & - \\
\hline Severe & 21 & 53 & - \\
\hline Infarct size $(\mathrm{cm})$ & & & 0.664 \\
\hline$<2$ & 55 & 176 & - \\
\hline$\geq 2$ & 27 & 97 & - \\
\hline
\end{tabular}

with the non-depressed group $(\mathrm{P}=0.666)$. During the 2 year follow-up, the KPS of patients in both groups significantly increased $(\mathrm{P}<0.001$ for the depressed group; $\mathrm{P}<0.001$ for the non-depressed group). The mean KPS in the depressed and non-depressed groups increased to 64.756 (SD, 13.719) and 70.183 (SD, 18.893), respectively. It was observed that the KPS of patients in the depressed group was significantly lower than those in the non-depressed group ( $\mathrm{P}=0.016$; Fig. 2A).

The differences of QOL between the depressed and non-depressed group were analyzed. It was observed that there were no significant differences in the scores of QOL between the depressed and non-depressed groups at admission $(\mathrm{P}=0.738)$. At the 12-month follow-up, the QOL scores of patients in both groups significantly decreased $(\mathrm{P}<0.001$ for the depressed group; $\mathrm{P}<0.001$ for the non-depressed group); however, the QOL of patients in the depressed group was significantly lower compared with the non-depressed group $(\mathrm{P}<0.001$; Fig. 2B).

PSD and outcomes of patients. In total, 23 patients did not survive the 2-year follow-up, of which 6 were depressed and 17 were not depressed; the mortality of patients in the depressed group patients was slightly higher compared with the non-depressed group (7.3\% for depressed cases; $6.2 \%$ for non-depressed cases). In Cox regression analysis, the risk of mortality in the depressed group increased by $49.7 \%$ compared with the non-depressed group after adjusting confounders; however, this difference was not significantly different $\left(\mathrm{HR}=1.497 ; 95 \% \mathrm{CI}, 0.547-4.098 ; \mathrm{P}_{\text {trend }}=0.432\right)$. In the analysis of stroke recurrence, it was observed that the incidence of stroke recurrence in the depressed group was higher compared with the non-depressed group (30.5\% for depressed cases; $17.6 \%$ for non-depressed cases), and the risk of stroke recurrence in the depressed group increased two-fold compared with the non-depressed group after adjusting confounders (HR=2.020; 95\% CI, 1.123-3.635; $\mathrm{P}_{\text {trend }}=0.019$; Table III).

\section{Discussion}

In the present study, the association between the expression levels of cytokines at admission, both acute inflammatory and proinflammatory, and the incidence of PSD during the 2 year follow-up in patients following ischemic stroke, was investigated. The results indicate that an increased serum IL-6 expression level is associated with the risk of PSD in patients who have experienced ischemic stroke. However, there were no significant associations between circulating expression levels of CRP, IL-1 $\beta$, IL- 2 and TNF- $\alpha$, and PSD. In addition, the effect of PSD on the outcome of patients was investigated, and it was observed that the risk of stroke recurrence in patients with PSD following ischemic stroke was higher compared with those without PSD.

The overall occurrence of PSD in the present study was $\sim 23 \%$, which is similar to, or lower than, the prevalence of depression reported in patients following ischemic stroke by other researchers (30). The incidence of depression in post-stroke has been reported with a large range (5-41\%), depending on the study and the methodology used $(31,32)$. In the current study, no association was found between the presence of depression and gender, education, smoking, alcohol assumption, marriage, hemisphere and infarct location. However, it was observed that patients $<50$ years of age occupy a larger proportion of patients with depression. In the authors' clinical work, it was identified that younger patients appear to be more concerned about the prognosis of the disease $(33,34)$. The factors that have an important role in the psychological state of younger patients requires further study.

Inflammatory cytokines have been shown to access the brain and interact with pathophysiological functions known to be involved in depression, including neurotransmitter metabolism, neuroendocrine function and neural plasticity (35). Monoamines are understood to be important mood-relevant neurotransmitters (36). It has been suggested that IL-1, TNF- $\alpha$, IL-6 and IFN- $\alpha$ may exert important roles in monoamine synthesis and reuptake, thus contributing to reduce 
Table II. Association of serum inflammatory cytokines concentrations with the risk of depression in patients following ischemic stroke in quartiles based on serum concentration.

\begin{tabular}{|c|c|c|c|c|c|}
\hline Parameter & 1 & 2 & 3 & 4 & $\mathrm{P}_{\text {trend }}{ }^{\mathrm{a}}$ \\
\hline $\mathrm{CRP}$ mean $\pm \mathrm{SD}, \mathrm{mg} / \mathrm{l}$ & $1.14 \pm 0.29$ & $1.86 \pm 0.23$ & $2.67 \pm 0.33$ & $4.99 \pm 2.32$ & - \\
\hline $\operatorname{HR}(95 \% \mathrm{CI})^{\mathrm{b}}$ & 1.00 (reference) & $0.67(0.33-1.37)$ & $0.84(0.42-1.69)$ & $0.96(0.49-1.88)$ & 0.928 \\
\hline $\operatorname{HR}(95 \% \mathrm{CI})^{\mathrm{c}}$ & 1.00 (reference) & $0.73(0.34-1.55)$ & $0.90(0.44-1.86)$ & $1.07(0.52-2.21)$ & 0.695 \\
\hline Cases (n) & 22 & 17 & 20 & 23 & - \\
\hline Controls (n) & 63 & 73 & 68 & 69 & - \\
\hline $\mathrm{IL}-1 \beta$ mean $\pm \mathrm{SD}, \mathrm{pg} / \mathrm{ml}$ & $4.74 \pm 1.67$ & $9.01 \pm 2.09$ & $13.30 \pm 1.97$ & $21.64 \pm 8.05$ & - \\
\hline $\operatorname{HR}(95 \% \mathrm{CI})^{\mathrm{b}}$ & 1.00 (reference) & $0.77(0.37-1.60)$ & $1.11(0.56-2.21)$ & $1.27(0.65-2.49)$ & 0.344 \\
\hline $\operatorname{HR}(95 \% \mathrm{CI})^{\mathrm{c}}$ & 1.00 (reference) & $0.79(0.38-1.69)$ & $1.23(0.59-2.55)$ & $1.29(0.64-2.60)$ & 0.306 \\
\hline Cases (n) & 21 & 16 & 21 & 24 & - \\
\hline Controls (n) & 72 & 71 & 65 & 65 & - \\
\hline $\mathrm{IL}-2$ mean $\pm \mathrm{SD}, \mathrm{pg} / \mathrm{ml}$ & $4.91 \pm 1.21$ & $7.99 \pm 0.67$ & $10.69 \pm 1.18$ & $18.62 \pm 4.76$ & - \\
\hline $\operatorname{HR}(95 \% \mathrm{CI})^{\mathrm{b}}$ & 1.00 (reference) & $0.93(0.46-1.88)$ & $1.07(0.53-2.15)$ & $1.04(0.51-2.08)$ & 0.831 \\
\hline $\operatorname{HR}(95 \% \mathrm{CI})^{\mathrm{c}}$ & 1.00 (reference) & $1.07(0.51-2.25)$ & $1.19(0.58-2.49)$ & $1.24(0.59-2.62)$ & 0.519 \\
\hline Cases (n) & 20 & 20 & 21 & 21 & - \\
\hline Controls (n) & 67 & 72 & 66 & 68 & - \\
\hline $\mathrm{IL}-6$ mean $\pm \mathrm{SD}, \mathrm{pg} / \mathrm{ml}$ & $5.03 \pm 1.39$ & $8.96 \pm 1.36$ & $13.57 \pm 1.56$ & $23.15 \pm 6.28$ & - \\
\hline $\operatorname{HR}(95 \% \mathrm{CI})^{\mathrm{b}}$ & 1.00 (reference) & $2.38(1.05-5.40)$ & $2.92(1.31-6.52)$ & $3.23(1.45-7.20)$ & 0.004 \\
\hline $\operatorname{HR}(95 \% \mathrm{CI})^{\mathrm{c}}$ & 1.00 (reference) & $2.56(1.05-5.97)$ & $2.69(1.18-6.16)$ & $3.18(1.37-7.36)$ & 0.011 \\
\hline Cases (n) & 10 & 21 & 25 & 26 & - \\
\hline Controls (n) & 77 & 68 & 66 & 62 & - \\
\hline $\mathrm{TNF}-\alpha$ mean $\pm \mathrm{SD}, \mathrm{pg} / \mathrm{ml}$ & $5.95 \pm 1.38$ & $9.84 \pm 1.40$ & $14.94 \pm 1.53$ & $25.84 \pm 5.24$ & - \\
\hline $\operatorname{HR}(95 \% \mathrm{CI})^{\mathrm{b}}$ & 1.00 (reference) & $1.18(0.57-2.42)$ & $1.22(0.60-2.47)$ & $1.36(0.67-2.75)$ & 0.406 \\
\hline $\operatorname{HR}(95 \% \mathrm{CI})^{\mathrm{c}}$ & 1.00 (reference) & $1.27(0.60-2.67)$ & $1.46(0.69-3.03)$ & $1.27(0.61-2.65)$ & 0.476 \\
\hline Cases (n) & 18 & 20 & 22 & 22 & - \\
\hline Controls (n) & 71 & 67 & 71 & 64 & - \\
\hline
\end{tabular}

${ }^{\text {aP }}$ for trend is based on quartile trend variable and all Ps are two-sided. ${ }^{\mathrm{b}} \mathrm{Crude}$ data analysis. HR and $95 \% \mathrm{CI}$ have no adjustments. ${ }^{\mathrm{c}} \mathrm{HR}$ and $95 \% \mathrm{CI}$ after adjusting for age, gender, education, smoking, alcohol assumption, marriage, hemisphere, stroke severity, infarct size and infarct sites. CRP, C reactive protein; $\mathrm{SD}$, standard deviation; HR, hazar radio; CI, confidence interval; IL, interleukin, TNF- $\alpha$, tumor necrosis factor- $\alpha$.

A

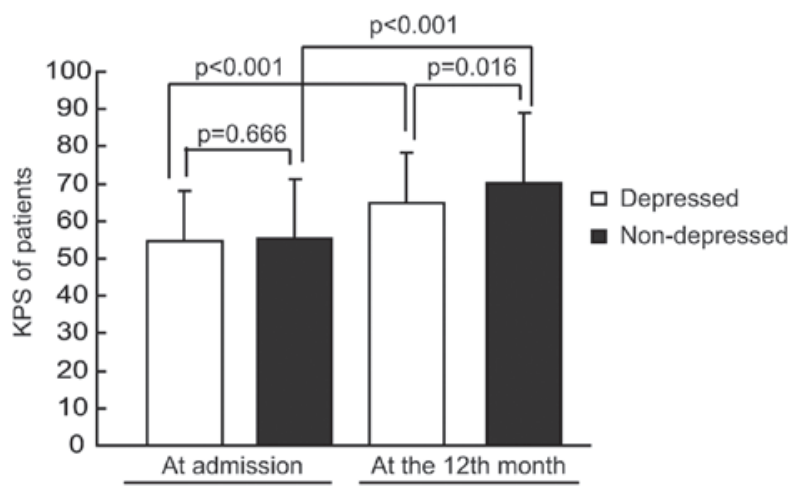

B

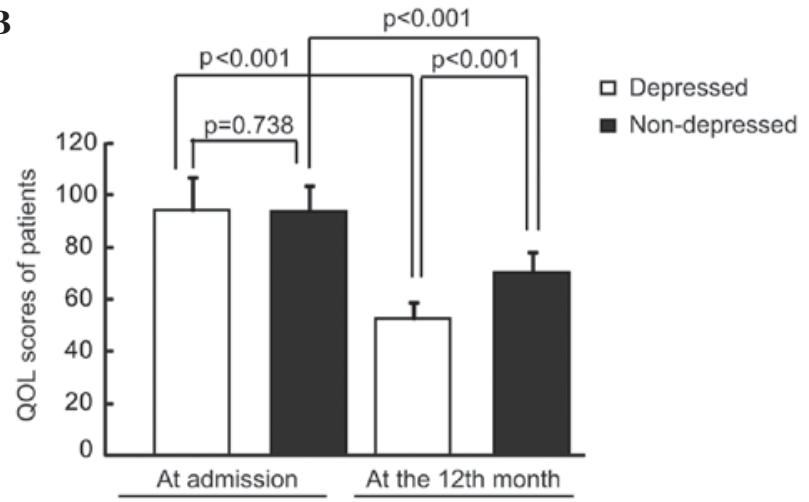

Figure 2. Effects of post-stroke depression on body performance and quality of life in patients. (A) KPS and (B) QOL scores in patients. KPS, Karnofsky Performance Status scale; QOL, quality of life.

monoamine availability (37-40). Furthermore, dysregulation of the hypothalamic-pituitary-adrenal axis is involved in depressive disorder (41). The secretion of corticotrophin-releasing hormone, adrenocorticotropic hormone and cortisol are stimulated by proinflammatory cytokines, such as IL-1, TNF- $\alpha$, IL-6 and IFN- $\alpha$ (42-48). Cytokines are important for providing trophic support to neurons and enhancing neurogenesis, which contributes towards normal cognitive functions, such as memory $(49,50)$. Evidence has demonstrated that increased concentrations of TNF- $\alpha$ and IL-1 in the hippocampus are 
Table III. Association between post-stroke depression and the outcomes of patients.

\begin{tabular}{|c|c|c|c|}
\hline Outcome & Not depressed $(n=273)$ & Depressed (n=82) & $\mathrm{P}_{\text {trend }}{ }^{\mathrm{a}}$ \\
\hline \multicolumn{4}{|l|}{ Mortality } \\
\hline Events, n (\%) & $17(6.2)$ & $6(7.3)$ & - \\
\hline Unadjusted $\mathrm{HR}^{\mathrm{b}}$ & 1 & 1.189 & 0.725 \\
\hline $95 \% \mathrm{CI}$ & Reference & $0.453-3.121$ & - \\
\hline Adjusted $\mathrm{HR}^{\mathrm{c}}$ & 1 & 1.497 & 0.432 \\
\hline $95 \% \mathrm{CI}$ & Reference & $0.547-4.098$ & - \\
\hline \multicolumn{4}{|l|}{ Recurrence of stroke } \\
\hline No. of events (\%) & $48(17.6)$ & $25(30.5)$ & - \\
\hline Unadjusted $\mathrm{HR}^{\mathrm{b}}$ & 1 & 2.056 & 0.012 \\
\hline $95 \% \mathrm{CI}$ & Reference & $1.170-3.614$ & - \\
\hline Adjusted $\mathrm{HR}^{\mathrm{c}}$ & 1 & 2.020 & 0.019 \\
\hline $95 \% \mathrm{CI}$ & Reference & $1.123-3.635$ & - \\
\hline
\end{tabular}

${ }^{\text {a }} \mathrm{P}$ for trend is based on binary trend variable and all Ps are two-sided. ${ }^{\mathrm{b}} \mathrm{Crude}$ data analysis. HR and $95 \% \mathrm{CI}$ have no adjustments. ${ }^{\mathrm{c}} \mathrm{HR}$ and $95 \% \mathrm{CI}$ after adjusting for age, gender, education, smoking, alcohol assumption, marriage, hemisphere, stroke severity, infarct size and infarct sites. HR, hazard ratio; CI, confidence interval.

associated with a decreased expression of brain-derived neurotrophic factor and its receptor, and reduced hippocampal neurogenesis (51). This evidence suggests that inflammatory cytokines may serve an important role in the occurrence and development of depression. However, in the present study, only increased serum IL-6 expression levels were significantly associated with the risk of PSD in patients following ischemic stroke. In the current study, blood collection was performed at the first fasting time after admission. It is understood that IL-6 is released by activated microglia within the central nervous system in stroke (52), and this release is mirrored by increased peripheral IL-6 concentrations (53), which trigger the subsequent release of CRP from the liver (54). Thus, the expression of inflammatory cytokines may fluctuate with time in the plasma. Further research is required to confirm this.

Stroke frequently results in a large number of changes in a stroke survivor's life, including loss of health, occupation, social role and independence (32). Depression is a common occurrence following stroke (55). In addition to the emotional well-being of the stroke survivor, the recognition and treatment of depression is important, as depression is associated with increased disability, increased cognitive impairment, and increased suicidality, mortality and poor rehabilitation outcomes (32). In the present study, it was observed that the KPS of patients with depression was significantly reduced compared with patients without depression, and the risk of stroke recurrence in patients with depression was higher compared with those without depression. It has previously been demonstrated that depression can impede recovery and has been linked with poorer treatment outcomes and increased durations in hospital (56). In communication with patients' families, it has been identified that the treatment compliance of patients with depression is worse compared with patients without depression, and such patients are resistant to rehabilitation training (57). This may be a cause of lower KPS and QOL scores, and high incidence of stroke recurrence, in patients with PSD. However, no significant risk of mortality was observed in the patients with PSD. This may be a result of the short follow-up period, and therefore the authors will continue to investigate on the effect of depression on the outcomes of patients.

There are a number of potential limitations to the current study. Firstly, although patients were not in an infectious state at the time of assessment, factors that may confound the measurement of cytokines were not considered, including stress, environment, obesity, diabetes, circadian rhythm or comedications. Secondly, the majority of patients visited Wuxi People's Hospital of Nanjing Medical University in the first instance; however, a number of patients obtained medical therapies prior to their visit to the hospital. Of those patients, it was unknown whether they were administered steroid therapies. This may conduct bias in the result of inflammatory cytokines. Thirdly, the blood sample collections were performed on admission. During the follow-up period, the changes in cytokine expression levels were not recorded in patients. This may also contribute to bias in the results. Fourthly, the mental status of patients may be affected by other factors, such as social, family or financial factors. In the present study, these were not taken into consideration. Despite this, the study may remain useful as it has a prospective design with a large number of participants, and is one of the few studies to date with sufficient valid information to investigate the association between cytokines and the risk of PSD, and the effect of PSD on the outcomes in patients following ischemic stroke. In the analysis, the data from follow-up was relatively complete due to high-quality records for endpoint determination and the small loss to follow-up of patients. In addition, information on several confounders was available for adjustment.

In conclusion, the results of the present study demonstrate a significant association between increased serum IL-6 expression levels with the risk of PSD following ischemic stroke. In addition, the results suggest that the outcomes of patients with depression following ischemic stroke are worse compared 
with patients without depression. Therefore, the results suggest a possible predictable effect of high expression levels of circulating IL-6 for PSD in patients following ischemic stroke. Further studies are required in order to elucidate the exact pathophysiological and biochemical mechanisms underlying depression associated with IL-6.

\section{Acknowledgements}

The present study work was supported by grants from the National Natural Science Foundation of China (grant nos. 81272791 and 81502159).

\section{References}

1. Lopez AD, Mathers CD, Ezzati M, Jamison DT and Murray CJ: Global and regional burden of disease and risk factors, 2001: Systematic analysis of population health data. Lancet 367 : $1747-1757,2006$

2. Eum Y and Yim J: Literature and art therapy in post-stroke psychological disorders. Tohoku J Exp Med 235: 17-23, 2015.

3. Hackett ML and Anderson CS: Predictors of depression after stroke: A systematic review of observational studies. Stroke 36 : 2296-2301, 2005

4. Evans DL, Charney DS, Lewis L, Golden RN, Gorman JM, Krishnan KR, Nemeroff CB, Bremner JD, Carney RM, Coyne JC, et al: Mood disorders in the medically ill: Scientific review and recommendations. Biol Psychiatry 58: 175-189, 2005.

5. Lindén T, Blomstrand C and Skoog I: Depressive disorders after 20 months in elderly stroke patients: A case-control study. Stroke 38: 1860-1863, 2007

6. Pan A, Sun Q, Okereke OI, Rexrode KM and Hu FB: Depression and risk of stroke morbidity and mortality: A meta-analysis and systematic review. JAMA 306: 1241-1249, 2011.

7. Schulz R, Beach SR, Ives DG, Martire LM, Ariyo AA and Kop WJ: Association between depression and mortality in older adults: The Cardiovascular Health Study. Arch Intern Med 160: $1761-1768,2000$

8. Pohjasvaara T, Vataja R, Leppävuori A, Kaste $\mathrm{M}$ and Erkinjuntti T: Depression is an independent predictor of poor long-term functional outcome post-stroke. Eur J Neurol 8 315-319, 2001

9. House A, Knapp P, Bamford J and Vail A: Mortality at 12 and 24 months after stroke may be associated with depressive symptoms at 1 month. Stroke 32: 696-701, 2001.

10. Liu CS, Adibfar A, Herrmann N, Gallagher D and Lanctot KL: Evidence for inflammation-associated depression. Current Top Behav Neurosci, 2016.

11. Connor TJ and Leonard BE: Depression, stress and immunological activation: The role of cytokines in depressive disorders. Life Sci 62: 583-606, 1998.

12. Dentino AN, Pieper CF, Rao MK, Currie MS, Harris T, Blazer DG and Cohen HJ: Association of interleukin-6 and other biologic variables with depression in older people living in the community. J Am Geriatr Soc 47: 6-11, 1999.

13. Tiemeier H, Hofman A, van Tuijl HR, Kiliaan AJ, Meijer J and Breteler MM: Inflammatory proteins and depression in the elderly. Epidemiology 14: 103-107, 2003.

14. Berk M, Wadee AA, Kuschke RH and O'Neill-Kerr A: Acute phase proteins in major depression. J Psychosom Res 43: 529-534, 1997.

15. Kop WJ, Gottdiener JS, Tangen CM, Fried LP, McBurnie MA, Walston J, Newman A, Hirsch C and Tracy RP: Inflammation and coagulation factors in persons $>65$ years of age with symptoms of depression but without evidence of myocardial ischemia. Am J Cardiol 89: 419-424, 2002.

16. Penninx BW, Kritchevsky SB, Yaffe K, Newman AB Simonsick EM, Rubin S, Ferrucci L, Harris T and Pahor M: Inflammatory markers and depressed mood in older persons: Results from the Health, Aging and Body Composition study. Biol Psychiatry 54: 566-572, 2003.

17. Ford DE and Erlinger TP: Depression and C-reactive protein in US adults: Data from the Third National Health and Nutrition Examination Survey. Arch Intern Med 164: 1010-1014, 2004.
18. Panagiotakos DB, Pitsavos C, Chrysohoou C, Tsetsekou E, Papageorgiou C, Christodoulou G and Stefanadis C; ATTICA study: Inflammation, coagulation and depressive symptomatology in cardiovascular disease-free people; the ATTICA study. Eur Heart J 25: 492-499, 2004.

19. Kuo HK, Yen CJ, Chang CH, Kuo CK, Chen JH and Sorond F: Relation of C-reactive protein to stroke, cognitive disorders and depression in the general population: Systematic review and meta-analysis. Lancet Neurol 4: 371-380, 2005.

20. ElAli A and Jean LeBlanc N: The role of monocytes in ischemic stroke pathobiology: New avenues to explore. Front Aging Neurosci 8: 29, 2016.

21. Rothenburg LS, Herrmann N, Swardfager W, Black SE, Tennen G, Kiss A, Gladstone DJ, Ween J, Snaiderman A and Lanctôt KL: The relationship between inflammatory markers and post stroke cognitive impairment. J Geriatr Psychiatry Neurol 23: 199-205, 2010.

22. McKechnie F, Lewis S and Mead G: A pilot observational study of the association between fatigue after stroke and C-reactive protein. J R Coll Physicians Edinb 40: 9-12, 2010.

23. Su JA, Chou SY, Tsai CS and Hung TH: Cytokine changes in the pathophysiology of poststroke depression. Gen Hosp Psychiatry 34: 35-39, 2012.

24. Jiménez I, Sobrino T, Rodríguez-Yáñez M, Pouso M, Cristobo I, Sabucedo M, Blanco M, Castellanos M, Leira R and Castillo J: High serum levels of leptin are associated with post-stroke depression. Psychol Med 39: 1201-1209, 2009.

25. Yang L, Zhang Z, Sun D, Xu Z, Zhang X and Li L: The serum interleukin-18 is a potential marker for development of post-stroke depression. Neurol Res 32: 340-346, 2010.

26. Brott T, Adams HP, Jr., Olinger CP, Marler JR, Barsan WG, Biller J, Spilker J, Holleran R, Eberle R, Hertzberg V, et al: Measurements of acute cerebral infarction: A clinical examination scale. Stroke 20: 864-870, 1989.

27. Steer RA, Clark DA, Beck AT and Ranieri WF: Common and specific dimensions of self-reported anxiety and depression: the BDI-II versus the BDI-IA. Behav Res Ther 37: 183-190, 1999.

28. The World Health Organization Quality of Life assessment (WHOQOL): Position paper from the World Health Organization. Soc Sci Med 41: 1403-1409, 1995.

29. Schag CC, Heinrich RL and Ganz PA: Karnofsky performance status revisited: Reliability, validity, and guidelines. J Clin Oncology 2: 187-193, 1984

30. Robinson RG and Jorge RE: Post-stroke depression: A review. Am J Psychiatry 173: 221-231, 2016.

31. Andersen G, Vestergaard K, Riis J and Lauritzen L: Incidence of post-stroke depression during the first year in a large unselected stroke population determined using a valid standardized rating scale. Acta Psychiatr Scand 90: 190-195, 1994

32. Whyte EM and Mulsant BH: Post stroke depression: Epidemiology, pathophysiology and biological treatment. Biol Psychiatry 52: 253-264, 2002.

33. Carota A, Berney A, Aybek S, Iaria G, Staub F, Ghika-Schmid F, Annable L, Guex P and Bogousslavsky J: A prospective study of predictors of poststroke depression. Neurology 64: 428-433, 2005.

34. Karamchandani RR, Vahidy F, Bajgur S, Vu KY, Choi HA, Hamilton RK, Rahbar MH and Savitz SI: Early depression screening is feasible in hospitalized stroke patients. PloS One 10: e0128246, 2015

35. Miller AH, Maletic V and Raison CL: Inflammation and its discontents: The role of cytokines in the pathophysiology of major depression. Biol Psychiatry 65: 732-741, 2009.

36. Miller AH: Norman Cousins Lecture. Mechanisms of cytokine-induced behavioral changes: Psychoneuroimmunology at the translational interface. Brain Behav Immun 23: 149-158, 2009.

37. Raison CL, Borisov AS, Majer M, Drake DF, Pagnoni G, Woolwine BJ, Vogt GJ, Massung B and Miller AH: Activation of central nervous system inflammatory pathways by interferon-alpha: Relationship to monoamines and depression. Biol Psychiatry 65: 296-303, 2009.

38. Capuron L, Neurauter G, Musselman DL, Lawson DH, Nemeroff CB, Fuchs D and Miller AH: Interferon-alpha-induced changes in tryptophan metabolism. Relationship to depression and paroxetine treatment. Biol Psychiatry 54: 906-914, 2003.

39. Kitagami T, Yamada K, Miura H, Hashimoto R, Nabeshima T and Ohta T: Mechanism of systemically injected interferon-alpha impeding monoamine biosynthesis in rats: Role of nitric oxide as a signal crossing the blood-brain barrier. Brain Res 978: 104-114, 2003. 
40. Zhu CB, Blakely RD and Hewlett WA: The proinflammatory cytokines interleukin-lbeta and tumor necrosis factor-alpha activate serotonin transporters. Neuropsychopharmacology 31: 2121-2131, 2006.

41. Besedovsky HO and del Rey A: Immune-neuro-endocrine interactions: Facts and hypotheses. Endocr Rev 17: 64-102, 1996.

42. Felger JC, Alagbe O, Hu F, Mook D, Freeman AA, Sanchez MM, Kalin NH, Ratti E, Nemeroff CB and Miller AH: Effects of interferon-alpha on rhesus monkeys: A non-human primate model of cytokine-induced depression. Biol Psychiatry 62: 1324-1333, 2007.

43. Capuron L, Raison CL, Musselman DL, Lawson DH, Nemeroff CB and Miller AH: Association of exaggerated HPA axis response to the initial injection of interferon-alpha with development of depression during interferon-alpha therapy. Am J Psychiatry 160: 1342-1345, 2003.

44. Harbuz MS, Chover-Gonzalez AJ and Jessop DS: Hypothalamo-pituitary-adrenal axis and chronic immune activation. Ann N Y Acad Sci 992: 99-106, 2003.

45. Raison CL, Borisov AS, Woolwine BJ, Massung B, Vogt G and Miller AH: Interferon-alpha effects on diurnal hypothalamic-pituitary-adrenal axis activity: Relationship with proinflammatory cytokines and behavior. Mol Psychiatry 15: 535-547, 2010.

46. Rich T, Innominato PF, Boerner J, Mormont MC, Iacobelli S, Baron B, Jasmin C and Lévi F: Elevated serum cytokines correlated with altered behavior, serum cortisol rhythm and dampened 24-hour rest-activity patterns in patients with metastatic colorectal cancer. Clin Cancer Res 11: 1757-1764, 2005.

47. Maes M, Bosmans E, Meltzer HY, Scharpé S and Suy E: Interleukin-1 beta: A putative mediator of HPA axis hyperactivity in major depression? Am J Psychiatry 150: 1189-1193, 1993.

48. Vedder H, Schreiber W, Schuld A, Kainz M, Lauer CJ, Krieg JC, Holsboer F and Pollmächer T: Immune-endocrine host response to endotoxin in major depression. J Psychiatr Res 41: 280-289, 2007.
49. Bernardino L, Agasse F, Silva B, Ferreira R, Grade S and Malva JO: Tumor necrosis factor-alpha modulates survival, proliferation and neuronal differentiation in neonatal subventricular zone cell cultures. Stem Cells 26: 2361-2371, 2008.

50. Goshen I, Kreisel T, Ounallah-Saad H, Renbaum P, Zalzstein Y, Ben-Hur T, Levy-Lahad E and Yirmiya R: A dual role for interleukin-1 in hippocampal-dependent memory processes. Psychoneuroendocrinology 32: 1106-1115, 2007.

51. Wu CW, Chen YC, Yu L, Chen HI, Jen CJ, Huang AM, Tsai HJ, Chang YT and Kuo YM: Treadmill exercise counteracts the suppressive effects of peripheral lipopolysaccharide on hippocampal neurogenesis and learning and memory. J Neurochem 103: 2471-2481, 2007.

52. Muir KW, Tyrrell P, Sattar N and Warburton E: Inflammation and ischaemic stroke. Curr Opin Neurol 20: 334-342, 2007.

53. Tarkowski E, Rosengren L, Blomstrand C, Wikkelsö C, Jensen C, Ekholm S and Tarkowski A: Early intrathecal production of interleukin- 6 predicts the size of brain lesion in stroke. Stroke 26 : 1393-1398, 1995

54. Pepys MB and Hirschfield GM: C-reactive protein: A critical update. J Clin Invest 111: 1805-1812, 2003.

55. Burvill PW, Johnson GA, Jamrozik KD, Anderson CS, Stewart-Wynne EG and Chakera TM: Prevalence of depression after stroke: The Perth Community Stroke Study. Br J Psychiatry 166: 320-327, 1995.

56. Aben I, Denollet J, Lousberg R, Verhey F, Wojciechowski F and Honig A: Personality and vulnerability to depression in stroke patients: A 1-year prospective follow-up study. Stroke 33: 2391-2395, 2002

57. Gillen R, Tennen H, McKee TE, Gernert-Dott P and Affleck G: Depressive symptoms and history of depression predict rehabilitation efficiency in stroke patients. Arch Phys Med Rehab 82: $1645-1649,2001$ 